\title{
Educação Ambiental e o Trabalho em Saúde: uma Análise das Experiências Profissionais do Brasil
}

\author{
Enviromental Education and the Public Health Work: an Analysis of Professional \\ Experiences in Brazil
}

\author{
Educación Ambiental y el Trabajo en Salud: un Análisis de las Experiencias \\ Profesionales de Brasil
}

\author{
Nilva Lúcia Rech Stedile ${ }^{1}$ \\ Ana Maria Paim Camardelo ${ }^{2}$ \\ Fernanda Meire Cioato ${ }^{3}$
}

\begin{abstract}
Resumo
As influências ambientais sobre a saúde são inequívocas; no entanto, decorrem de ações que podem ser mediadas. Este trabalho objetiva analisar como profissionais da saúde têm utilizado a educação ambiental como objeto de trabalho para a saúde ambiental. Utilizou-se como metodologia um estudo documental, desenvolvido por meio da análise de relatos de experiência de práticas de educação ambiental disponíveis na Comunidade de Práticas da Atenção Básica, Ministério da Saúde e Governo Federal. Essas comunidades concentram a descrição de experiências profissionais práticas. Em relação à abrangência territorial, o Nordeste e o Sudeste são as regiões que mais desenvolvem ações educativas e a maior parte dos trabalhos concentra-se em saúde ambiental/vigilância ambiental (71,79\%). O espaço de escolha para o desenvolvimento das ações é prioritariamente em comunidade/município, seguida da escola, os quais representam mais de $90 \%$ do total e os públicos mais envolvidos são a população de um bairro/cidade e estudantes. O tema mais utilizado como mobilizador das ações educativas em educação ambiental é a dengue $(69,24 \%)$ e as técnicas educativas mais utilizadas nas atividades são curso/palestras tradicionais. A educação ambiental precisa ser desenvolvida permanentemente com uso de estratégias que proporcionem reflexão crítica, a fim de alcançar os objetivos de formação cidadã e protetiva do ambiente e da saúde.
\end{abstract}

Palavras-chave: Técnicas educativas. Educação ambiental. Saúde ambiental.

\begin{abstract}
Environmental effects on health are significant; however, they result from actions that can be mediated. This work aims to analyze how health professionals have used environmental education as a tactic to improve environmental health. A documentary study was used as methodology, developed through analysis of practical experiences reports of environmental education from the Community of Primary Care Practices, Ministry of Health and Federal Government. These communities concentrated on describing practical professional experiences. In relation to the geographic scope, the Northeast and Southeast are the regions that most commonly implement educational initiatives and the greater part of the actions concentrates on Environmental Health/Environmental Surveillance (71.79\%). The place chosen for the development of actions is primarily in communities/municipalities, followed by schools, which represent more than $90 \%$ of the total and the most active participant in environmental education is the population of a district/city and students. The most common topic covered in environmental education is dengue $(69.24 \%)$ and the educational techniques most commonly used include traditional courses and lectures.
\end{abstract}

1 Doutora em Enfermagem pela Universidade Federal de São Paulo e Pós-doutorado em Informação e Comunicação em Saúde do ICICT/Fiocruz. Professora titular na Área do Conhecimento de Ciências da Saúde da Universidade de Caxias do Sul e no Mestrado Profissional em Engenharias e Ciências Ambientais (PPGECAM). E-mail: nlrstedi@ucs.br

${ }^{2}$ Doutora em Serviço Social pela Pontifícia Universidade Católica do Rio Grande do Sul. Professora na Área do Conhecimento de Humanidades da Universidade de Caxias do Sul e no Programa de Pós-Graduação em Direito (PPGDIR) e Programa de Pós-Graduação em Psicologia (PPGPSI). E-mail: ampcamar@ucs.br

${ }^{3}$ Acadêmica de Enfermagem na Universidade de Caxias do Sul. Bolsista de iniciação científica (PIBIC-CNPq) no projeto intitulado Segregação de Resíduos Sólidos Urbanos em Caxias do Sul: Proposição e Implementação de um Projeto de Educação Ambiental. Bolsista do Programa de Educação pelo Trabalho para a Saúde PETSaúde/Interprofissionalidade do Ministério da Saúde e da Educação. E-mail: fmcioato@ucs.br 
Environmental education needs to be developed permanently, using strategies that allow for critical reflection, to achieve the objectives of an active citizenship and protection of the environment and health.

Keywords: Educational techniques. Environmental education. Environmental health.

\section{Resumen}

Las influencias ambientales sobre la salud son inequívocas, pero se derivan de acciones que pueden ser mediadas. El objetivo del estudio es analizar cómo profesionales de la salud han utilizado la educación ambiental como objeto de trabajo para la salud ambiental. Se utilizó como metodología un estudio documental, desarrollado por medio del análisis de relatos de experiencia en prácticas de educación ambiental disponibles en la Comunidad de Prácticas de la Atención Básica, Ministerio de Salud y Gobierno Federal. Estas comunidades concentran la descripción de experiencias profesionales prácticas. En cuanto al alcance territorial, el Nordeste y el Sudeste son las regiones que más desarrollan acciones educativas, y la mayor parte de los trabajos se concentra en Salud Ambiental/Vigilancia Ambiental (71,79\%). El espacio de elección para el desarrollo de las acciones es prioritariamente en Comunidad/Municipio, seguida de la escuela, que representan más del $90 \%$ del total, y los públicos más involucrados son la Población de un barrio/ciudad y estudiantes. El tema más utilizado como movilizador de las acciones educativas en educación ambiental es el dengue (69,24\%), y las técnicas educativas más utilizadas en las actividades son cursos/conferencias, de carácter tradicional. La educación ambiental necesita ser desarrollada permanentemente con el uso de estrategias que proporcionen reflexión crítica, a fin de alcanzar los objetivos de formación ciudadana y protectora del ambiente y de la salud.

Palabras clave: Técnicas educativas. Educación ambiental. Salud ambiental.

\section{Introdução}

O consumo de bens materiais tem contribuído para modificar o ambiente em acentuadas proporções no decurso dos anos. A transformação do meio ambiente corrobora o desequilíbrio de uma série de outros fatores associados que são fundamentais às necessidades humanas básicas, como a saúde. Esta pode ser entendida como um produto de diversas variáveis que a condicionam, dentre elas, o ambiente equilibrado. As influências ambientais na saúde são decorrentes de ações que podem ser mediadas, pois cerca de $24 \%$ da carga global de doença e um terço da carga de doenças sobre crianças (0-14 anos) se devem a fatores ambientais modificáveis (WHO, 2016).

Nas últimas décadas, as questões ambientais foram pauta de diferentes conferências mundiais, como a Conferência de Estocolmo (1972), a Eco-92 (1992), a Rio +10 (2002) e a Rio +20 (2012), a fim de buscar novas práticas para o desenvolvimento sustentável (UNITED NATIONS, 1972; 1992; 2002; 2012). No entanto, percebe-se que, em nível da saúde, o ambiente não tem sido o foco central de atuação profissional e os métodos de intervenção são insuficientes para colaborar na transformação da problemática ambiental e da sua influência sobre a qualidade de vida.

Visando proporcionar melhores condições de vida, o Ministério da Saúde (MS) vem desenvolvendo um sistema de Vigilância em Saúde Ambiental em todo o país, no âmbito do Sistema Único de Saúde (SUS), a fim de constituir "competências que objetivam a implementação de ações em que é constatada a relação entre saúde humana, degradação e contaminação ambiental" (BRASIL, 2007). Essas ações são realizadas, sobretudo, por profissionais que procuram alterar fatores que são condicionantes ao desequilíbrio do meio ambiente, especialmente na Atenção Básica. É imposto ao Poder Público e à coletividade a defesa e a preservação do meio ambiente, uma vez que é essencial à qualidade de vida (BRASIL, 1988).

Como estratégia transformadora, a Educação Ambiental (EA) se constitui como um instrumento pedagógico capaz de problematizar a realidade por meio de técnicas educativas, 
podendo desenvolver um novo significado e modificar realidades associadas ao meio ambiente e à Saúde Ambiental (SA). De acordo com a Política Nacional de Educação Ambiental,

Entendem-se por educação ambiental os processos por meio dos quais o indivíduo e a coletividade constroem valores sociais, conhecimentos, habilidades, atitudes e competências voltadas para a conservação do meio ambiente, bem como de uso comum do povo, essencial à sadia qualidade de vida e sua sustentabilidade (BRASIL, 1999).

A problematização do que é habitual e o estímulo à reflexão propiciam a tomada de consciência crítica, realizados por métodos educativos, os quais podem se constituir em um meio para prevenção e controle de fatores de risco ambientais relacionados à saúde. A educação ambiental, como política educativa, visa que a cidadania seja desenvolvida para a mudança como garantia da qualidade de vida (PELICIONI, 2014).

Essa ferramenta, conforme Mazzarino e Rosa (2013), por possibilitar as interrelações socioambientais, é capaz de oportunizar a compreensão da realidade e de tornar seres protagonistas de alternativas que lhe asseguram melhor qualidade de vida. Desse modo, este estudo teve como objetivo analisar como os profissionais da área têm utilizado a educação ambiental como objeto de trabalho para a saúde ambiental, com base em relatos de experiência em um instrumento virtual do MS intitulado Comunidade de Práticas, o qual hospeda experiências práticas desses profissionais em todo o território nacional.

\section{Metodologia}

O enquadre metodológico deste trabalho pode ser referido como documental, desenvolvido por meio de uma análise de relatos de experiência disponíveis na Comunidade de Práticas da Atenção Básica, Ministério da Saúde/Governo Federal em dezembro de 2017. Na página da Comunidade de Práticas estavam disponíveis, naquela data, 8.116 relatos de experiência desenvolvidos no Brasil (8116 RELATOS..., 2017), no âmbito do SUS.

Utilizou-se o filtro de "Educação Ambiental", que resultou em 2.658 relatos. Dentre os filtros que estavam disponíveis na categoria, foram utilizados: "Controle social e participação popular", "Equidade e populações específicas", "Intersetorialidade e promoção da saúde" e "Práticas de vigilância em saúde", que se relacionavam com a educação ambiental e totalizaram 421 relatos.

A análise de conteúdo dos dados qualitativos dos 421 relatos foi realizada como a proposta por Bardin (2016): a) pré-análise dos relatos de experiência; b) classificação dos dados e desenvolvimento de tabelas analíticas; e c) interpretações dos resultados. Construíram-se critérios de análise específicos para os relatos e foram descartados os que descreviam experiências em educação em saúde, educação popular em saúde e educação permanente em saúde, sem vinculação com a saúde ambiental. Foram considerados como critério de seleção os que relataram a utilização de uma técnica educativa para a educação ambiental como instrumento para a saúde e para a saúde ambiental. Após essa análise, foram selecionados 124 relatos.

Posteriormente à classificação inicial dos relatos, passou-se para a fase de análise em profundidade. Os relatos foram distribuídos por espaço territorial brasileiro (Centro-Oeste, Nordeste, Norte, Sudeste e Sul) e classificou-se como "não consta" para aqueles que não especificavam a localidade em que a prática educativa foi realizada. Em relação ao foco da ação educativa desenvolvida, os relatos foram distribuídos em "Saúde ambiental/vigilância ambiental", "Formação de agentes ambientais" e "Empreendedorismo/desenvolvimento sustentável". 
O local onde as atividades educativas foram realizadas foi identificado, bem como categorizado o perfil do público envolvido e a abrangência das ações. As técnicas educativas utilizadas foram distribuídas conforme a prática desenvolvida com o público, e também especificado o tema dos relatos de experiência de educação ambiental.

Os dados de natureza quantitativa foram tratados por estatística descritiva e apresentados em forma de tabela e figuras.

\section{Resultados}

A partir dos 8.116 relatos disponíveis na página da Comunidade de Práticas/MS (8116 RELATOS..., 2017) em dezembro de 2017 foram analisados os dados de interesse e apresentados em quatro tabelas e três figuras, as quais representam o panorama geral das ações de educação ambiental desenvolvidas pelos profissionais de saúde no SUS.

Esses dados estão organizados em três seções: abrangência territorial das práticas em EA; lócus de desenvolvimento de práticas de EA; e técnicas educativas em EA e seus temas.

\subsection{Abrangência territorial das práticas em EA}

Os 124 relatos sobre educação ambiental analisados foram distribuídos por região brasileira e seus estados, de acordo com a Tabela 1.

Tabela 1 - Distribuição das atividades educativas por região brasileira

\begin{tabular}{|c|c|c|c|}
\hline Região & Estados & $\mathbf{N}$ & $\%$ \\
\hline Nordeste & $\begin{array}{l}\text { Bahia } \\
\text { Ceará } \\
\text { Paraíba } \\
\text { Pernambuco } \\
\text { Piauí } \\
\text { Rio Grande do Norte }\end{array}$ & 44 & 35,5 \\
\hline Sudeste & $\begin{array}{l}\text { Espírito Santo } \\
\text { Minas Gerais } \\
\text { Rio de Janeiro } \\
\text { São Paulo }\end{array}$ & 39 & 31,45 \\
\hline Sul & $\begin{array}{l}\text { Paraná } \\
\text { Rio Grande do Sul } \\
\text { Santa Catarina }\end{array}$ & 18 & 14,51 \\
\hline Norte & $\begin{array}{l}\text { Amazonas } \\
\text { Pará } \\
\text { Rondônia }\end{array}$ & 12 & 9,67 \\
\hline Centro-Oeste & $\begin{array}{l}\text { Distrito Federal } \\
\text { Goiás } \\
\text { Mato Grosso } \\
\text { Mato Grosso do Sul }\end{array}$ & 8 & 6,45 \\
\hline Não consta & Não consta & 3 & 2,42 \\
\hline TOTAL & & 124 & 100 \\
\hline
\end{tabular}

Fonte: elaboração das autoras (2018).

Das regiões brasileiras, a região Nordeste é a que realiza mais atividades de educação ambiental, seguida da região Sudeste e Sul. Do total de relatos analisados, as regiões Norte e Centro-Oeste são as que menos desenvolvem atividades educativas com foco na educação ambiental. Destaca-se ainda que o Nordeste, mesmo sendo a região que mais desenvolve essas 
atividades, não o faz em todos os estados que a compõe; o mesmo ocorre com as regiões CentroOeste e Norte. As regiões Sudeste e Sul desenvolveram atividades em todos seus estados constituintes.

Cabe destacar que, conforme os dados do Censo 2010, a região Nordeste possui 27,85\% da população brasileira, que lhe confere posição de segunda região mais populosa do Brasil, atrás da região Sudeste, a qual contempla 42,12\% da população (IBGE, 2010a). Ao que isso indica, a região Sudeste, mesmo sendo a mais populosa, não é a que mais desenvolve práticas educativas voltadas ao ambiente. No entanto, em relação ao IDHM (Índice de Desenvolvimento Humano Municipal), o Nordeste possui 0,659, o qual lhe atribui a média mais baixa quando comparado às demais regiões brasileiras (IBGE, 2010b), o que pode ser uma das razões para que desenvolva tais atividades, especialmente se considerarmos que grande parte dos relatos estão relacionados à prevenção das infecções causadas pelo mosquito Aedes aegypti.

Em levantamento da prática de educação ambiental publicada em revistas acadêmicas brasileiras realizado por Viegas e Neiman (2015), mostrou-se que, sob o aspecto formal, a região Sudeste, seguida pela região Sul, concentra o maior percentual. Esse fator pode estar relacionado à maior concentração de mestrados e doutorados nessas regiões, o que favorece a publicação científica. Destaca-se que os relatos nas Comunidades de Práticas referem-se a experiências de trabalho que podem ser divulgadas livremente e a qualquer tempo no site do MS.

Além disso, de acordo com a Agenda 21 (2004), o desafio ambiental mais amplo da região Nordeste consiste na garantia de ampliação do recurso água e que seja potável à população da região, por meio da conscientização para o seu uso racional, a fim de que a escassez relativa da água não permaneça como um obstáculo para o desenvolvimento sustentável. A qualidade da água tem sido tema de preocupação no campo da saúde ambiental, sobretudo no Nordeste, que é a região que mais desenvolve a educação por ACS (Agentes Comunitários de Saúde) voltada à qualidade da água $(52,8 \%)$ em relação às demais regiões brasileiras (STEDILE et al., 2016).

Conforme a Agenda 21 (2004), em debates regionais, as regiões Norte, Centro-Oeste e Nordeste mostraram-se mais preocupadas com o modelo de desenvolvimento e a proteção dos biomas nacionais. No entanto, as regiões Norte e Centro-Oeste apresentam baixo índice de uso de tecnologias para a educação ambiental, se considerada a necessidade de aplicá-las em seus territórios conforme os princípios específicos definidos por essas regiões para modificação do modelo de desenvolvimento e preservação dos biomas.

O Gráfico 1 apresenta a distribuição em percentuais dos trabalhos de educação ambiental, classificados de acordo com seu foco de atuação, ou seja, trabalhos relacionados à "Saúde ambiental e vigilância ambiental"; "Formação de agentes ambientais" e "Empreendedorismo/desenvolvimento sustentável".

Gráfico 1 - Distribuição dos trabalhos por categoria 


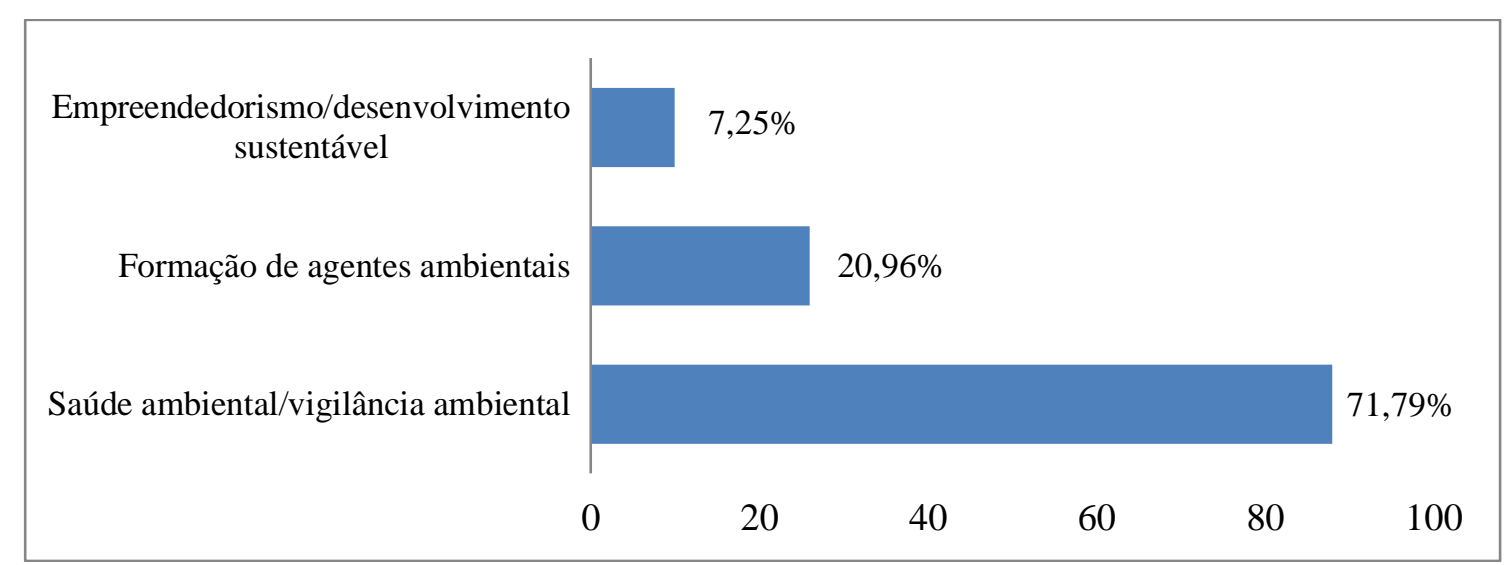

Fonte: elaboração das autoras (2018).

Percebe-se que a "Saúde ambiental/vigilância ambiental" é a categoria que concentra a maior parte das atividades educativas conforme o Gráfico 1. Essas atividades são exercidas, sobretudo, pelas ACS, e voltadas ao combate a vetores responsáveis pela transmissão de doenças, especialmente a dengue. Dada a importância da saúde ambiental, a complexidade do tema e seus múltiplos aspectos, a concentração dos trabalhos nessa dimensão pode ser considerada insuficiente para a melhoria das condições de saúde da população, especialmente se considerado que grande parte das doenças que acometem a população brasileira tem como força motriz a qualidade ambiental, incluindo a água, o ar e o solo.

As ações voltadas à formação de agentes ambientais e ao empreendedorismo/desenvolvimento sustentável são as menos investidas no campo ambiental. Desse modo, a formação de multiplicadores de conhecimentos e o desenvolvimento ligado à sustentabilidade não têm sido suficientemente utilizada como estratégia para a conservação do meio ambiente e da saúde e para o desenvolvimento da saúde ambiental.

Mota (2005), em seus estudos, divide em três grandes grupos o foco de exercício multidisciplinar necessário a profissionais de diferentes áreas: i) saneamento básico e saúde pública no campo ambiental; ii) gestão ambiental; e iii) áreas de conhecimentos importantes (engenharia e meio ambiente, engenharia sanitária e ambiental, engenharia de segurança e medicina do trabalho, gestão e recursos hídricos e educação ambiental) para a realização de atividades, a fim de garantir qualidade de vida e contribuir na preservação dos recursos naturais, em conjunto. $\mathrm{O}$ resultado do processo de planejamento acontece quando as comunidades as quais se dirigem as intervenções são ativas nas decisões, "sentem o efeito dos benefícios propostos e percebem reflexos positivos nos espaços locais, e em suas interações regionais, que se traduzem em qualidade ambiental" (PHILIPPI JÚNIOR; ROMÉRO; BRUNA, 2014, p. 11). Assim, em processos bem conduzidos de formação de agentes ambientais, os participantes têm maior probabilidade de se tornarem protagonistas e corresponsáveis pelas transformações necessárias nos comportamentos que levem à proteção ambiental.

\subsection{Lócus de desenvolvimento de práticas de EA}

As práticas de EA podem ser desenvolvidas em ambientes de ensinos formais, não formais e informais (BRASIL, 1999). Ambientes formais referem-se à desenvolvida em instituições de ensino formais, públicos ou privados. Os ambientes não formais são considerados todos os espaços comunitários, nos quais as ações para sensibilização em relação ao meio ambiente são voltadas à coletividade (CÂMARA, 2017). No Gráfico 2 estão os locais onde as ações educativas têm sido desenvolvidas. 
Gráfico 2 - Distribuição dos trabalhos por local onde as atividades educativas foram realizadas

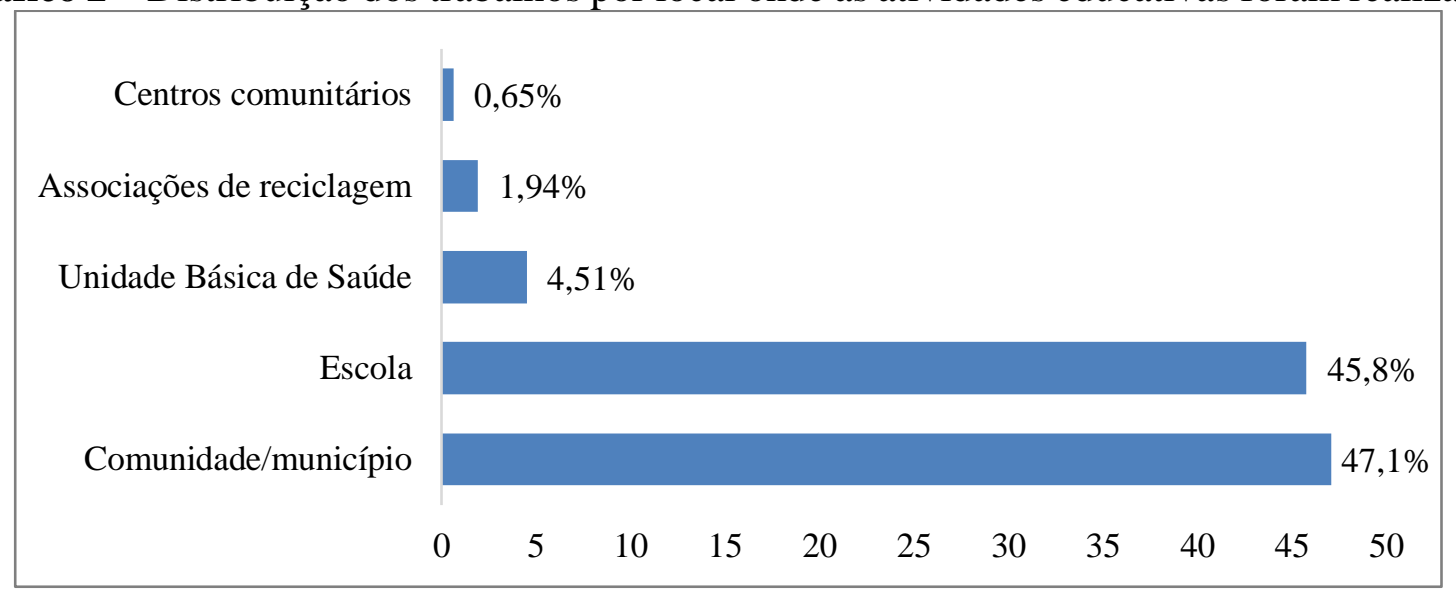

Fonte: elaboração das autoras (2018).

Das experiências da Atenção Básica, conforme o Gráfico 2, as práticas desenvolvidas em comunidade/município perfazem $47,10 \%$ e nas escolas, $45,80 \%$, sendo essas últimas desenvolvidas prioritariamente por ACS. Os trabalhos educativos sob aspecto de ensino formal e informal são abrangidos; no entanto, ambientes como UBS, associações de reciclagem e centros comunitários mostram um número reduzido de ações. Cabe destacar que as práticas realizadas na comunidade e no município, referem-se, em sua maioria, à prática de vigilância ambiental domiciliar.

Para Córdula et al. (2015), é necessária a implantação de métodos efetivos em educação ambiental não formal junto às comunidades e, por meio da sensibilização, buscar a conservação dos recursos naturais e do ecossistema. Constituem-se como desafio dos educadores as novas demandas socioeducacional e cultural, que precisam ultrapassar os limites formais e regulares da escola (MUNHOZ; MAZZARINO, 2015).

O público abrangido pelas atividades de EA pode ser visto na Tabela 2.

Tabela 2 - Distribuição das atividades educativas segundo público envolvido

\begin{tabular}{llcc}
\hline Alcance & Público envolvido & $\mathbf{N}$ & \% \\
\hline Direcionado a & *População & 40 & 32,33 \\
um público & Estudantes & 28 & 22,58 \\
\hline Direcionado a & Estudantes/população & 15 & 12,00 \\
dois ou mais & Estudantes/professores & 09 & 7,25 \\
públicos & Estudantes/pais & 06 & 4,83 \\
& Estudantes/professores/população & 05 & 4,0 \\
& Estudantes/professores/funcionários/população/pais & 03 & 2,0 \\
& Estudantes/professores/população/pais & 02 & 2,0 \\
& Estudantes/professores/funcionários & 01 & 0,8 \\
& Estudantes/professores/pais & 01 & 0,8 \\
& Estudantes/professores/funcionários/pais & 01 & 0,8 \\
\hline Outros & & 09 & 7,25 \\
\hline Não consta & & 04 & 3,36 \\
\hline TOTAL & & 124 & 100 \\
\hline
\end{tabular}

*População de um bairro/cidade

Fonte: elaboração das autoras (2018). 
Em relação ao público, percebe-se que mais da metade das ações são direcionadas a um público específico $(54,91 \%)$, sendo distribuídas para a população de um bairro/cidade $(32,33 \%)$ ou para estudantes $(22,58 \%)$. Cabe destacar que 34,48\% das ações têm abrangência maior, dirigem-se a dois ou mais públicos, como estudantes/população ou estudantes/pais. Disso resulta que as ações preferencialmente têm sido direcionadas a públicos específicos. Isso é adequado especialmente quando o objetivo é a formação de agentes ambientais. Em relação ao local do desenvolvimento das atividades na perspectiva do espaço favorecedor de aprendizagem, a escola é o lócus preferencial de atuação dos profissionais de saúde, conforme mostra a Tabela 3 .

Tabela 3 - Distribuição das atividades segundo local de desenvolvimento das atividades educativas

\begin{tabular}{llcc}
\hline Abrangência & Espaço de aprendizagem & $\mathbf{N}$ & $\mathbf{\%}$ \\
\hline Local único & Escola & 40 & 32,25 \\
& Comunidade & 37 & 29,83 \\
& Município & 07 & 5,60 \\
\hline Dois ou mais & Escola/comunidade & 17 & 13,70 \\
locais & Escola/outros & 02 & 1,71 \\
& Escola/comunidade/outros & 02 & 1,71 \\
\hline Outros & & 15 & 12,00 \\
\hline Não consta & & 04 & 3,20 \\
\hline TOTAL & & 124 & 100 \\
\hline
\end{tabular}

Fonte: elaboração das autoras (2018).

De acordo com a Tabela 3, grande parte das experiências em EA foi desenvolvida na escola. A escola se constitui um ambiente no qual há um movimento contínuo de retroalimentação sociocultural e se tem convívio de diferentes realidades sociais (MAZZARINO; ROSA, 2013). Por isso se constitui como um ambiente favorecedor para o processo de EA, no sentido de relação e construção de conhecimentos em diversas vivências. Assim, as técnicas para desenvolver a educação ambiental precisam ser escolhidas de modo a instigar o interesse do público escolar (GOMES et al., 2016). Quando o ambiente escolar não consegue compor as demandas sociais necessárias, é essencial o investimento em alternativas educacionais (MUNHOZ; MAZZARINO, 2015).

Para Chagas e Andrade (2014) é ainda um desafio formular o processo educativo ambiental crítico e inovador em níveis formal e não formal e se faz necessário tanto enfatizar a relação entre o homem, a natureza e o universo como referenciar o protagonismo do ser humano que degrada os recursos naturais.

No aspecto do público envolvido, os resultados mostraram que as técnicas ambientais se direcionam, em sua maior parcela, a um único local, ou seja, a um público-alvo. Como revela Gomes et al. (2016), precisa-se sensibilizar e conscientizar de maneira a atingir os indivíduos em uma maior escala. Para isso, é fundamental que a EA seja articulada de forma intersetorial com objetivo de abranger diferentes públicos. Assim, pode contribuir no entendimento da complexidade ambiental e o envolvimento coletivo em defesa do meio ambiente, como prevê a Política Nacional do Meio Ambiente: "educação ambiental a todos os níveis de ensino, inclusive a educação da comunidade, objetivando capacitá-la para participação ativa na defesa do meio ambiente" (BRASIL, 1981). 


\subsection{Técnicas educativas em EA e seus temas}

As técnicas educativas são estratégias que, por meio de uma experiência de ensino, potencializam um aprendizado. As técnicas que mais têm sido utilizadas e seus respectivos temas estão na Tabela 4.

Tabela 4 - Distribuição das técnicas educativas utilizadas nas atividades

\begin{tabular}{|c|c|c|c|}
\hline Técnicas & Descrição & $\mathbf{N}$ & $\%$ \\
\hline Curso/palestras & $\begin{array}{l}\text { Dengue } \\
\text { Formação de agente ambiental } \\
\text { Horticultura orgânica } \\
\text { Meio ambiente } \\
\text { Orientação psicológica } \\
\text { Parasitose } \\
\text { Reunião comunitária } \\
\text { Saúde ambiental }\end{array}$ & 59 & 21,70 \\
\hline $\begin{array}{l}\text { Jogos/ludicidade } \\
\text { Gincana/concurso }\end{array}$ & $\begin{array}{l}\text { Álbum ilustrativo, apresentação de } \\
\text { trabalho, concurso de desenho, } \\
\text { documentário, fotografias, gincana, } \\
\text { jogos, maquete, paródia, texto e } \\
\text { vídeo }\end{array}$ & 54 & 19,85 \\
\hline Visita domiciliar & Visita domiciliar & 36 & 13,25 \\
\hline $\begin{array}{lr}\text { Confecção } & \text { de } \\
\text { histórias } & \text { em } \\
\text { quadrinhos } & \\
\text { Cartazes/fôlders } & \end{array}$ & $\begin{array}{l}\text { Elaboração de aplicativo } \\
\text { Confecção de cartaz, cartilha, } \\
\text { faixa/placa, panfleto } \\
\text { Painel } \\
\text { Programa de televisão } \\
\text { Revista em quadrinhos }\end{array}$ & 33 & 12,13 \\
\hline Arte & $\begin{array}{l}\text { Dança } \\
\text { Música } \\
\text { Teatro (dengue e fantoches) }\end{array}$ & 27 & 9,92 \\
\hline $\begin{array}{l}\text { Atividades práticas } \\
\text { em situações reais }\end{array}$ & $\begin{array}{l}\text { Construção armadilhas (dengue) } \\
\text { Coleta e reciclagem de óleo } \\
\text { Construção de horta } \\
\text { Identificação de focos de dengue } \\
\text { Reflorestamento }\end{array}$ & 32 & 11,76 \\
\hline Oficinas & $\begin{array}{l}\text { Artesanato, dança, dengue, resíduos } \\
\text { sólidos }\end{array}$ & 13 & 4,77 \\
\hline Roda de conversa & $\begin{array}{l}\text { Dengue, doenças diarreicas, saúde } \\
\text { ambiental e sustentabilidade }\end{array}$ & 13 & 4,77 \\
\hline Laboratório & Microscópio & 03 & 1,10 \\
\hline Seminário & Dengue & 02 & 0,75 \\
\hline TOTAL & & 272 & 100 \\
\hline
\end{tabular}

Fonte: elaboração das autoras (2018).

Das práticas descritas na Comunidade de Práticas, conforme a Tabela 4, 21,70\% referem-se a curso/palestra, seguido de atividades lúdicas (19,85\%) e visita domiciliar 
$(13,25 \%)$. Percebe-se que há uma diversidade de técnicas educativas; no entanto, predomina o uso de palestras como estratégia para aprendizagem em EA.

A escolha predominante por palestras e cursos remete a uma pedagogia mais conservadora, denominada diretiva, segundo Becker (1994). Não significa que uma técnica educativa em si pode ser caracterizada como diretiva ou não diretiva, uma vez que a forma como é utilizada caracteriza os tipos de resultados que podem ser obtidos em termos de aprendizagem. De qualquer forma, é função do educador problematizar a temática abordada aos educandos e não dissertar sobre ela (PELICIONI, 2005).

Para Ribeiro e Cavassan (2016), muitas técnicas educativas utilizam modelos pedagógicos que, na prática, não repercutem com o que o discurso idealiza, como a consciência de responsabilidade, igualdade, respeito e democracia. Diante da condição que permeia as questões ambientais, pode-se dizer que as escolhas dos métodos adequados podem não estar atingindo reais significados.

A palestra é o recurso de maior utilização para atingir o público formal e não formal. Nas práticas desenvolvidas por Santos (2014), a discussão da problemática por meio desse recurso gera cansaço e desinteresse pronunciado pelos próprios espectadores. A utilização de palestras, oficinas, cursos e reuniões não proporcionará a formação pedagógica de forma única, faz-se necessário que seja contínua, permanente, estimule a criticidade no cotidiano e, sobretudo, oportunize a relação entre os indivíduos e o ambiente (MAZZARINO; ROSA, 2013). Nessa perspectiva, oficinas, gincanas, teatros, imersões em situações reais, elaborações de documentários e proposta de rádio e TV, por exemplo, têm maior potencial para gerar essa aprendizagem.

A escolha do método adequado deve variar conforme o público que se envolve na prática educativa e os objetivos de aprendizagem a atingir. Devido a isso, nenhuma técnica se constitui como completamente adequada em si mesma. Dessa forma, cabe ao educador julgar a mais apropriada de acordo com o momento e o conteúdo a ser exposto (CHAGAS; ANDRADE, 2014) e, principalmente, as habilidades e competências a serem desenvolvidas para que o indivíduo esteja apto a cuidar do meio ambiente e, por consequência, da saúde. No contexto da EA, ainda há um descompasso entre o objetivo da aprendizagem e o método de intervenção (RIBEIRO; CAVASSAN, 2016).

Conforme Munhoz e Mazzarino (2015), a maneira de educar vem percorrendo um modelo tradicional ao que deveria ser estésico e proporcionar a variação do modo de compreender o ambiente. Assim sendo, a experiência educativa deveria envolver o público como sujeito da realidade e objeto de aprendizagem que, por meio do entendimento de um novo significado, seja capaz de promover a mudança de comportamento.

Diante da variedade de estratégias metodológicas, Scupino e Kaick (2017) consideram que as baseadas na ludicidade são as mais favoráveis à sensibilização dos sujeitos. Em práticas pedagógicas em EA de Ferreira et al. (2012), os jogos lúdicos despertaram interesse e envolvimento na temática pelo estímulo à participação nas atividades, uma vez que contribui para uma aprendizagem mais significativa e provavelmente contínua. Dessa forma, a ludicidade, por meio de brincadeiras e atividades práticas, passa a ser um instrumento de aprendizagem que pode construir valores e conceitos ambientais (CÂMARA, 2017).

Baseados em um modelo o qual impacte todos os membros, Ribeiro e Cavassan (2016) acreditam que o trabalho em grupo maximiza a aprendizagem, visto que nessa configuração o objetivo é alcançado se todos os demais também atingirem. Os elementos a serem ensinados e apreendidos são nomeados como competências para os mesmos autores, os quais os indivíduos devem tornar-se responsáveis e críticos por meio do autoconhecimento, do saber conviver e relacionar-se com compreensão e solidariedade, serem agentes que cooperam para transformar a sociedade e respeitem os diferentes tipos de cultura no exercício da democracia e responsabilidade coletiva. 
Os temas desenvolvidos podem ser vistos no Gráfico 3.

Gráfico 3 - Distribuição das atividades educativas segundo o tema desenvolvido

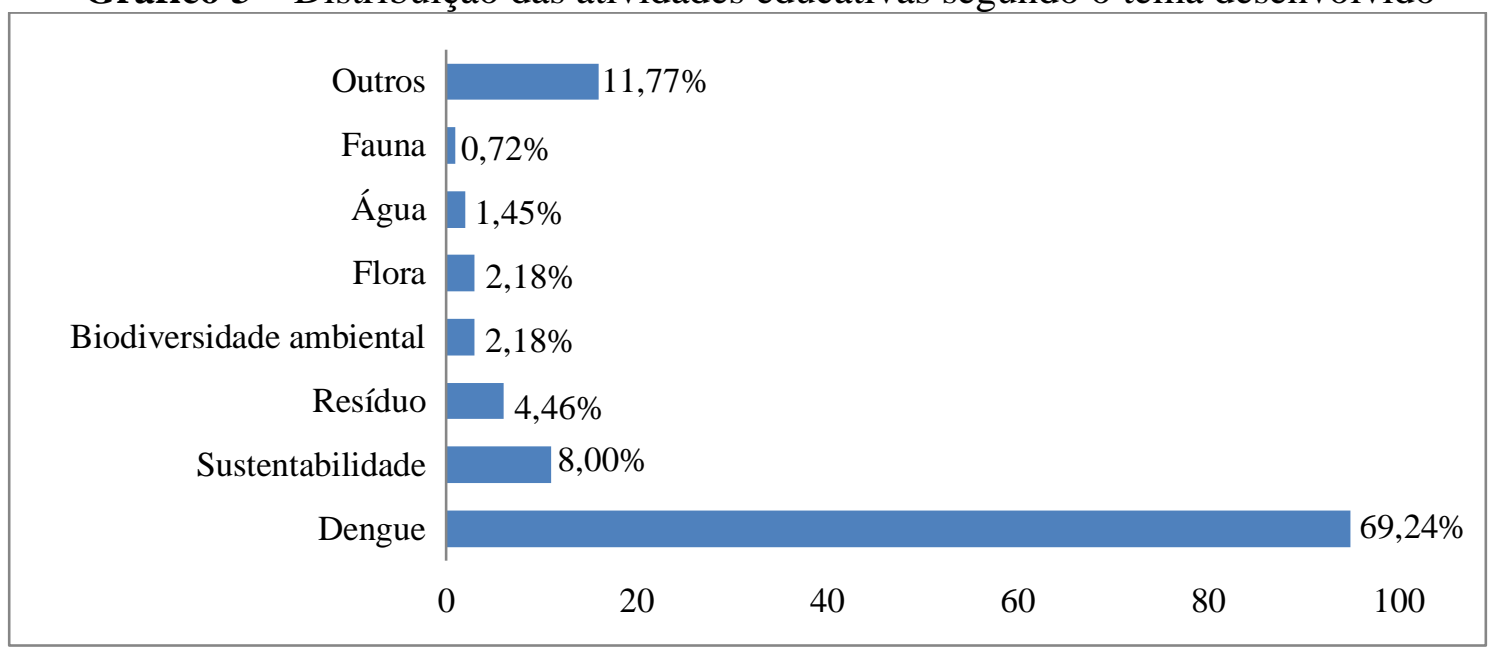

Fonte: elaboração das autoras (2018).

O Gráfico 3 mostra que a dengue $(69,24 \%)$ prevalece como tema ambiental mais abordado pelos profissionais de saúde, seguido de sustentabilidade (8\%) e resíduos $(4,46 \%)$. A concentração de ações na dengue sugere que a EA também é utilizada como forma de reagir aos problemas emergentes em relação à saúde. Ressalta-se que a EA deveria ser planejada e incluída como prática cotidiana do cuidado em saúde, uma vez que influi diretamente nos estados de saúde/doença de populações. Devido à complexidade dos problemas e as suas interrelações, é preciso envolver no processo uma equipe multidisciplinar que atue em todas as áreas em busca de um resultado possível (PHILIPPI JÚNIOR; ROMÉRO; BRUNA, 2014). É necessário ainda que essa equipe atue de forma interprofissional para dar conta da complexidade de aspectos presentes na relação entre saúde e meio ambiente.

De acordo com Chagas e Andrade (2014), é papel da educação ambiental desenvolver a percepção para que os indivíduos busquem a garantia da qualidade de vida e, consequentemente, a da sociedade como um todo. Para que isso se torne realmente efetivo, a aprendizagem cooperativa como prática educativa, que configura em dimensões sociológica, epistemológica, psicológica e didática, pode integrar um instrumento capaz de gerar ressignificação pelo conhecimento e experiência de mundos particulares, por meio de um diálogo de saberes para a "ampliação do meio ambiente individual dos sujeitos envolvidos nesse processo" (RIBEIRO; CAVASSAN, 2016, p. 32).

A EA é um mecanismo que possibilita o entendimento da causa dos problemas, a fim de se obter soluções para os problemas ambientais e do campo da saúde. Nesse sentido, metodologias educativas de diálogo com a comunidade podem desenvolver um movimento reflexivo sobre a realidade e proporcionar a construção de novas perspectivas de convívio homem-ambiente.

\section{Considerações finais}

A interface entre o meio ambiente e a saúde tem sido objeto de discussão, uma vez que suas relações interferem diretamente no estado de saúde individual e coletivo. Os resultados de análise dos relatos de experiência na Comunidade de Práticas do Ministério da Saúde (8116 RELATOS..., 2017) mostraram que: 
- as regiões Nordeste $(35,22 \%)$ e Sudeste $(31,45 \%)$ são as que mais desenvolvem atividades de EA nos contextos de trabalho em saúde;

- a saúde ambiental/vigilância ambiental concentra a maior parte das ações educativas $(71,79 \%)$;

- o local principal de desenvolvimento das ações educativas é a comunidade/município $(47,10 \%)$ e a escola $(45,80 \%)$; e os públicos mais envolvidos são a população de um bairro/cidade $(32,33 \%)$ e estudantes $(22,58 \%)$;

- o tema mais utilizado como mobilizador das ações educativas em EA é a dengue $(69,24 \%)$, seguida da sustentabilidade ambiental (8\%);

- as técnicas educativas mais utilizadas nas atividades são curso/palestras $(21,70 \%)$ e ludicidade $(19,85 \%)$.

No geral, o desenvolvimento de técnicas educativas para a EA no Brasil é escasso, dispersamente distribuído entre os estados/regiões brasileiras; e as ações realizadas, em sua maioria, foram em virtude da epidemia de dengue. Infere-se que não há uma política de educação ambiental consolidada no Brasil. $\mathrm{O}$ fato de que a maior parte das ações está sendo desenvolvida pelos ACS aponta para um envolvimento superficial da equipe interprofissional e interdisciplinar de saúde nesta complexa relação saúde e ambiente.

Fazem-se necessárias novas formas de atuação, além das formas tradicionais de saúde ambiental/vigilância ambiental em todas as regiões brasileiras no que se refere especificadamente à EA como estratégia para a saúde, saúde ambiental e ambiente, a fim de proporcionar melhor qualidade de vida à população.

A EA precisa ser desenvolvida por meio de um processo permanente, que promova estratégias que proporcionem a reflexão crítica dos cidadãos pela problematização, por uma relação horizontal entre educadores (profissionais) e educandos (usuários), para que sejam adotados comportamentos efetivos que favoreçam a qualidade de vida. Assim, é mais provável o desenvolvimento de habilidades aos envolvidos, de forma multidisciplinar, para lidar adequadamente com a prevenção e com problemas ambientais que interferem na saúde. É necessário que a Política Nacional de Educação Ambiental seja incorporada no cotidiano dos serviços, a fim de que se possa atuar nas causas dos problemas de saúde e não apenas nos sinais e sintomas de patologias instaladas.

\section{Referências}

8116 RELATOS de experiência para você se inspirar. Brasília, DF: Comunidade de Práticas, 2017. Disponível em: https://novo.atencaobasica.org.br/relato. Acesso em: 10 dez. 2017.

AGENDA 21. Resultado da consulta nacional. 2. ed. Brasília, DF: Ministério do Meio Ambiente, 2004. Disponível em: http://bit.ly/32LKDAg. Acesso em: 7 abr. 2018.

BARDIN, L. Análise de conteúdo. São Paulo: Edições 70, 2016.

BECKER, F. Modelos pedagógicos e modelos epistemológicos. Educação e Realidade, Porto Alegre, v. 19, n. 1, p. 89-96, 1994. Disponível em: http://bit.ly/35T630m. Acesso em: 2 out. 2019.

BRASIL. Constituição (1988). Constituição da República Federativa do Brasil. Brasília, DF: Presidência da República, 1988. Disponível em: http://bit.ly/35icHgx. Acesso em: 18 abr. 2019.

BRASIL. Lei $n^{\circ}$ 6.938, de 31 de agosto de 1981. Dispõe sobre a Política Nacional do Meio Ambiente, seus fins e mecanismos de formulação e aplicação, e dá outras providências. Diário Oficial da União, Brasília, DF, 2 set. 1981. Disponível em: http://bit.ly/35QG3CU. Acesso em: 21 abr. 2018. 
BRASIL. Lei n ${ }^{\circ} 9.795$ de 27 de abril de 1999. Dispõe sobre a educação ambiental, institui a Política Nacional de Educação Ambiental e dá outras providências. Diário Oficial da União, Brasília, DF, 28 abr. 1999. Disponível em: http://bit.ly/2Bu5Suq. Acesso em: 13 fev. 2018.

BRASIL. Subsídios para construção da Política Nacional de Saúde Ambiental. Brasília, DF: Editora MS, 2007. Disponível em: http://bit.ly/2P7Gh2K. Acesso em: 13 fev. 2018.

CÂMARA, V. O. F. A importância da educação ambiental lúdica: abordagens e reflexões para a construção do conhecimento infantil. Revbea, São Paulo, v. 12, n. 4, p. 60-75, 2017. Disponível em: http://bit.ly/2P4xkqH. Acesso em: 21 jan. 2018.

CHAGAS, F. B.; ANDRADE, V. Z. Compreendendo a educação ambiental: contribuição do processo de ensino-aprendizagem de biologia na escola. Ambiente e Educação, Rio Grande, v. 19, n. 1, p. 5976, 2014.

CÓRDULA, E. B. L. et al. Educação ambiental não formal para sensibilização do público infantojuvenil em assentamentos na Paraíba. Gaia Scientia, Paraíba, v. 9, n. 1, p. 74-88, 2015.

FERREIRA, P. M. L. et al. Educação Ambiental Lúdica na Escola Pública: contribuindo com o processo de engajamento e transformação social. Gaia Scientia, Paraíba, v. 6, n. 1, p. 7-18, 2012.

GOMES, C. M. R et al. Análise das práticas de educação ambiental em duas escolas de ensino médio na cidade de Juazeiro do Norte-CE. Gestão e Sustentabilidade Ambiental, Florianópolis, v. 5, n. 1, p. 26-41, 2016. Disponível em: http://bit.ly/32zT1CX. Acesso em: 22 jan. 2018.

INSTITUTO BRASILEIRO DE GEOGRAFIA E ESTATÍSTICA - IBGE. Censo Demográfico. Brasília, DF, 2010a. Disponível em: http://bit.ly/31xMN5n. Acesso em: 30 dez. 2017.

INSTITUTO BRASILEIRO DE GEOGRAFIA E ESTATÍSTICA - IBGE. Índice do Desenvolvimento Humano Municipal. Brasília, DF: Atlas do Desenvolvimento Humano no Brasil, 2010b. Disponível em: http://bit.ly/2p2R97b. Acesso em: 30 dez. 2017.

MAZZARINO, J. M.; ROSA, D. C. Práticas pedagógicas em educação ambiental: o necessário caminho da auto-formação. Ambiente e Educação, Rio Grande, v. 18, n. 2, p. 121-144, 2013.

MOTA, F. S. B. Conhecimentos para promoção do saneamento, saúde e ambiente. In: PHILIPPI JÚNIOR, A. (ed.). Saneamento, saúde e ambiente: fundamentos para um desenvolvimento sustentável. Barueri: Manole, 2005. p. 809-832.

MUNHOZ, A. V.; MAZZARINO, J. Cartografias e currículos-mapas: ecologia em espaços educativos não escolarizados. Pesquisa em Educação Ambiental, São Paulo, v. 10, n. 2, p. 109-123, 2015.

Disponível em: http://bit.ly/33RmuIV. Acesso em: 21 jan. 2018.

PELICIONI, M. C. F. Educação ambiental: evolução e conceitos. In: PHILIPPI JÚNIOR, A. (ed.). Saneamento, saúde e ambiente: fundamentos para um desenvolvimento sustentável. Barueri: Manole, 2005. p. 587-598.

PELICIONI, M. C. F. Fundamentos da educação ambiental. In: PHILIPPI JÚNIOR, A.; ROMÉRO, M.; BRUNA, G. C. (ed.). Curso de gestão ambiental. 2. ed. Barueri: Manole, 2014. p. 469-492.

PHILIPPI JÚNIOR, A.; ROMÉRO, M. A.; BRUNA, G. C. Uma introdução à gestão ambiental. In: PHILIPPI JÚNIOR, A.; ROMÉRO, M. A.; BRUNA, G. C. (ed.). Curso de gestão ambiental. 2. ed. Barueri: Manole, 2014. p. 3-18. 
RIBEIRO, J. A. G.; CAVASSAN, O. A adoção da aprendizagem cooperativa (AC) como prática pedagógica na educação ambiental (EA): possibilidades para o ensino e a aprendizagem de conteúdos conceituais, procedimentais e atitudinais. Pesquisa em Educação Ambiental, São Paulo, v. 11, n. 1, p. 19-36, 2016. Disponível em: http://bit.ly/31Cgmme. Acesso em: 21 jan. 2018.

SANTOS, A. C. V. Teatro na sala de aula: abordagem inovadora no ensino-aprendizagem no processo de educação ambiental. Ambiente e Educação, Rio Grande, v. 19, n. 2, p. 51-65, 2014.

SCUPINO, F.; KAICK, T. S. van. Avaliação de programas de educação ambiental voltados para gestão de resíduos sólidos em escolas municipais de Pinhais/PR. Pesquisa em Educação Ambiental, São Paulo, v. 12, n. 1, p. 71-84, 2017. Disponível em: http://bit.ly/2pGkqV8. Acesso em: 21 jan. 2018.

STEDILE, N. L. R. et al. As relações entre saúde, meio ambiente e qualidade da água na atenção básica: uma análise a partir dos resultados do PMAQ. In: CONGRESSO DE TECNOLOGIAS PARA O MEIO AMBIENTE, 5., 2016, Bento Gonçalves. Anais [...]. Bento Gonçalves, 2016. Disponível em: http://bit.ly/32C8ORY. Acesso em: 30 dez. 2017.

UNITED NATIONS. Report of the United Nations Conference on the Human Environment. Stockholm, 5-16 June 1972. New York, 2017. Disponível em: http://bit.ly/2MCExNj. Acesso em: 26 set. 2019.

UNITED NATIONS. Conference on environment \& development: Rio de Janeiro, Brazil, 3 to 14 June 1992. New York, 1992. Disponível em: http://bit.ly/31CVbQR. Acesso em: 26 set. 2019.

UNITED NATIONS. Report of the World Summit on Sustainable Development: Johannesburg, South Africa, 26 August 4 September 2002. New York, 2002. Disponível em: http://bit.ly/2pKsaFF. Acesso em: 26 set. 2019.

UNITED NATIONS. Report of the United Nations Conference on sustainable development: Rio de Janeiro, Brazil 20-22 June 2012. New York, 2012. Disponível em: http://bit.ly/2MZnZhl. Acesso em: 26 set. 2019.

VIEGAS, P. L.; NEIMAN, Z. A prática de educação ambiental no âmbito do ensino formal: estudos publicados em revistas acadêmicas brasileiras. Pesquisa em Educação Ambiental, São Paulo, v. 10, n. 2, p. 45-62, 2015. Disponível em: http://bit.ly/2Budayi. Acesso em: 4 fev. 2018.

WORLD HEALTH ORGANIZATION - WHO. Preventing disease through healthy environments: a global assessment of the burden of disease from environmental risks. Geneva, 2016. Disponível em: http://bit.ly/2J9be2I. Acesso em: 2 out. 2019. 